\title{
Post-traumatic stress disorder after watching violent scenes on television
}

\author{
K A L A Kuruppuarachchi', S S Williams ${ }^{2}$ and T Gadambanathan ${ }^{3}$
}

\section{Introduction}

Post-traumatic stress disorder (PTSD) is an intense, prolonged and sometimes delayed reaction to extremely stressful events such as natural disasters or man-made calamities, characterised by persistent hyperarousal, reexperiencing of images of the stressful event and avoidance of reminders (1). The disorder can become chronic and disabling with delay in treatment (2). PTSD can also be brought on in children, by viewing stressful scenes on television (3). Here we report two such cases.

\section{Case 1}

A 9-year old schoolboy from Gampaha was brought by his mother, as he had become extremely fearful of staying alone and was disturbed by nightmares over a period of 6 weeks. She had also noticed that there had been a decline in his interest in school work and that he did not engage in play as he used to. She was extremely concerned because her son had previously been a self-assured and outgoing child and had excelled in school work.

The mother clearly linked the onset of symptoms to a telecast of an assassination bid on a politician by a suicide bomber. A special television news bulletin had focussed on vivid scenes that included the mangled bodies of the dead, the decapitated body of the suicide bomber, and the injured being rushed to hospital.

One seeing this, the boy had become extremely fearful, started crying and had run out of the room requesting the parents to switch off the television immediately. He could not sleep and clung on to his mother saying he was scared because the vivid images shown were coming constantly into his mind. The parents finally distracted him sufficiently with pleasant bedtime stories and he fell asleep at 2 am.

Since that day, he refused to stay alone. A parent had to accompany him even to the toilet. Every evening he became extremely fearful and wanted the windows and doors shut. He awakened at night from his sleep, crying and complaining of fearful dreams. The child started asking his parents for a sedative antihistamine syrup before going to sleep. He refused to watch television, became extremely distressed when it was switched on and avoided being in its vicinity. His school performance dropped and he did not show his usual interest in hobbies such as drawing.

Previously he had no phobias or obsessional traits. He had many friends and took part in extra-curricular activities. He was a healthy child from birth and had normal developmental milestones. He has a 5-year old brother with whom he interacted well.

On mental state examination, he was anxious and clung to his mother. His speech was reduced. He was preoccupied with the thought that a bomb may explode close to his residence, at school or while travelling. He confessed to having intrusive images of the bomb blast scene each time he saw television. He had deficits in attention and concentration.

\section{Case 2}

A 5-year old girl was brought by her parents a month after having seen her hero in a popular television series being stabbed to death on screen. She had related the victim in the drama to her grandfather, and had become extremely distressed and tearful on seeing the killing. Since then she was having recurrent nightmares, fearful of staying alone, and refusing to mix with people other than her family members. She also refused to watch television. Her development had been previously normal and she had no major illnesses. On mental state examination, she was anxious and withdrawn. She could not be.drawn into a conversation.

\section{Management}

Both children were reassured and commenced on simplified cognitive behaviour therapy. The boy was gradually desensitised by way of drawings over a period of 4 weeks to rid him of fears for normal events. We saw him weekly with his mother as an outpatient, and he made a good recovery. The girl was reintroduced gradually to television and other activities with the aid of a star chart and reassurance by the parents. She too made a good recovery.

\section{Discussion}

The children had persistent anxiety, insomnia and poor concentration characteristic of a hyperarousal state. They had intense intrusive imagery - "flashbacks" - and recurring distressing dreams. They also avoided reminders of the event. There was significant distress or impairment in functioning for more than a month. A diagnosis of PTSD was made on Diagnostic and Statistical Manual of Mental Disorders Criteria (4).

However, the interesting fact was that the stressful event had not been directly experienced by the children, but was brought to their drawing room by television. Today, displaying scenes or pictures of a gory or violent nature are a common occurrence. Both the print and elec- 
tronic media are guilty of such exhibition and insensitivity. Although it may serve the purpose of bringing home the truth and reality, the effect it may have on people, especially on children, has not been given serious thought. Even the elderly may have PTSD triggered many years after the original trauma due to media coverage of related incidents (5). In several countries the audience is forewarned if any scenes are likely to be of a nature that may cause distress to the viewer.

\section{References}

1. Gelder M, Gath D, Mayou R, Cowen P. Oxford Textbook of
Psychiatry. $3^{\text {mi }}$ edition. Oxford: Oxford University Press, 1996: 140.

2. Creamer M, McFarlane A. Post-traumatic stress disorder. Australian Prescriber 1999; 22: 32-4.

3. Simons D, Silveira WR. Post-traumatic stress disorder in children after television programmes. British Medical Journal 1994; 308: 389-90.

4. American Psychiatric Association. Diagnostic and Statistical Manual of Mental Disorders. $4^{\text {th }}$ edition. Washington DC: American Psychiatric Association, 1994.

5. Hilton C. Media triggers of post-traumatic stress disorder 50 years after the Second World War. International Journal of Geriatric Psychiatry 1997; 12: 862-7.

\section{Drug effectiveness and efficiency}

Efficacy is not the same as effectiveness. A treatment is effective if it works in real life in non-ideal circumstances. In real life, medications will be used in doses and frequencies never studied and in patient groups never assessed in the trials. Drugs will be used in combination with other medications that have not been tested for interactions, and by people other than the patient - the 'over the garden fence' syndrome. Effectiveness cannot be measured in controlled trials, because the act of inclusion into a study is a distortion of usual practice. Effectiveness can be defined as the extent to which a drug achieves its intended effect in the usual clinical setting'. It can be evaluated through observational studies of real practice. This allows practice to be assessed in qualitative as well as quantitative terms.

Efficiency depends on whether a drug is worth its cost to individuals or society. The most efficacious treatment, based on the on best evidence, may not be the most cost effective option. It may not be acceptable to patients. In every country, rationing of health care is a reality. There is no country, however wealthy, that can afford to deliver all the health care possible to the whole of its population at all times. Rationing may be implicit or explicit, but it will happen. Good effectiveness and efficiency studies will make this rationing more informed.

Marley J. Efficacy, effectiveness, efficiency. Australian Prescriber 2000: 23:114-5 (Editorial). 